\title{
Student-Athlete or Athlete-Student: Analysis of Benefits and Barriers of University Sport Participation in South Africa
}

\author{
${ }^{1}$ Shadrack Nthangeni, ${ }^{2}$ Abel Toriola ${ }^{*},{ }^{2}$ Yvonne Paul, ${ }^{3}$ Vinessa Naidoo \\ ${ }^{1}$ Directorate of Sport and Recreation, Tshwane University of Technology, Pretoria, South \\ Africa. ${ }^{2}$ Department of Sport, Rehabilitation and Dental Sciences, Tshwane University of Technology, \\ Pretoria, South Africa. ${ }^{3}$ Business School, Faculty of Management Sciences, Tshwane University of \\ Technology, Pretoria, South Africa.
}

Submitted 29 July 2020; Accepted in final form 28 September 2020.

\begin{abstract}
Background. Universities are perceived as the hub for sports talent identification and development. This perception puts much pressure on student-athletes who are expected to excel in sport despite their academic commitments. Based on this expectation, students who participate in sports could be regarded as athlete-student, rather than student-athlete. Objectives. The study was carried out to investigate the perceptions of South African student-athletes about the benefits and challenges of participating in varsity sports. Methods. From an estimated study population of 1892, a sample of 203 (138 male and 65 female) student-athletes participating in athletics, football, netball, and rugby from four universities in Gauteng province of South Africa completed a self-report questionnaire on the benefits and barriers of sport participation. The overall reliability (Cronbach's alpha) coefficient of the questionnaire was 0.82 , and the content validity of the instrument was established. Results. The student-athletes' perceived benefits of varsity sports participation included enjoyment, to make their families proud, to make friendships, to complete their studies on record time, to receive performance-related incentives and awards, to be seen on television, and to be scouted by professional teams. Significant challenges faced by the student-athletes included match fixtures clashing with academic timetables, parents/guardians pressurizing them to excel academically, inadequate sporting equipment, fear of injury, and poor academic support needed to catch up with schoolwork. Conclusion. The current findings have practical implications for the promotion and management of varsity sports competitions in South African universities.
\end{abstract}

KEYWORDS: Student-Athletes, University, Varsity, Sports.

\section{INTRODUCTION}

Over the years, the sport has been a central aspect of South African life, operating at school, provincial, and national levels (1). Sport in South Africa can, however, be traced as far back as the colonial era, during which sport was regulated under a repressive system that took two forms, i.e., an advantageous establishment sector dominated by white people, and a disadvantaged, non-establishment sector mainly consisting of black South Africans (2, 3). After independence in 1994, sport became a powerful tool that could be used to move away from a discriminatory form of social order (1) to an egalitarian, just, and cohesive society. Consequently, a white paper on Sport and Recreation (4) was enacted in 1995, which promoted sports participation by all South Africans irrespective of gender, race, religion, disability, and socioeconomic backgrounds (5).

While the white paper on sport and recreation provided a broad framework for South Africa's

*. Corresponding Author:

Abel Toriola, Professor

E-mail: toriolaal@tut.ac.za 
sports promotion and development (6), very few studies have been conducted on university sports in the country. For example, Nolan, Sandada, and Surujlal (7) reported that improved health, physical performance, psychological outlook, and life enhancement were perceived as the significant benefits of sport participation among university students. The authors further identified a lack of facilities and fatigue as constraining factors to sport participation. In a study among university students in Pretoria, Kubayi, Nthangeni, Toriola, and Haycock (8) reported that students' participation in sport was affected mainly by time constraints, transport difficulties, and inadequate facilities. Although these studies have provided baseline information on the benefits and challenges associated with participation in university sports, there is limited research on competitive leagues such as varsity sports and cup competitions.

In South Africa, the varsity sports tournaments offer an exciting platform for universities to compete in sports such as athletics, beach volleyball, cricket, football, hockey, netball, rugby sevens, and others. These competitions also provide a unique opportunity for sponsors to connect with the university community through sport and entertainment. Therefore, sport remains one of the most powerful marketing platforms in South African society and has been a catalyst for change and nation-building (9).

Given that university student-athletes combine their studies with sport participation, they are susceptible to several challenges and stressful situations. Using a mixed-methods research design, Montagni et al. (10) investigated the physical activity and sport participation in a sample of 508 French students who completed a self-administered questionnaire and were interviewed. The authors identified the lack of time and students' need for more sport activities and less workload as solutions to their barriers to sport participation. In another study, Thomas et al. (11) examined the frequency, intensity, time, type of physical activity, and the barriers to sport participation among Canadian university students. They reported that the students experienced barriers to physical activity and sport engagement, which were characterized as intrapersonal (stress and perceived self-skill), interpersonal (lack of friends, and peer influence), and structural (homework, class schedule, and overcrowded facilities) constraints.

Despite the importance of sport participation for the wellbeing of students, previous studies concerning Varsity Sports and Varsity Cup competitions in South Africa could hardly be found. Therefore, several issues could be raised regarding university students' participation in organized sport: What are the benefits of sports participation to university students? What factors limit university students' sports engagement? In what ways can the constraints to students' sport participation be mitigated? The current study attempts to fill this gap in the literature by focusing on the benefits and challenges associated with university sport participation in the country. This study may provide new information on Varsity Sports and Cup competitions and give recommendations on aspects of the competitions which require future improvements. Also, the management of Varsity Sports and Cup competitions and Sport and Recreation South Africa can potentially use the study's insights and findings for effective promotion and management of sport in the universities. The purpose of this study was to examine perceptions of South African student-athletes about the benefits and challenges associated with varsity sport participation.

\section{MATERIALS AND METHODS}

Study Design and Sample Size. This study adopted a quantitative research approach in which 203 student-athletes (138 males and 65 females) were purposively recruited to participate in the study, from an estimated population of 1892 participants. The student-athletes who were drawn from four universities (the Tshwane University of Technology, Universities of Johannesburg, Pretoria, and Witwatersrand) participated in the following sports: cricket, football, netball, and rugby. Regarding race, the majority of them were Black Africans (56.2\%), followed by Whites (29.6\%) and Coloureds (13.3\%).

Research Instrument. A self-administered questionnaire adapted from literature (e.g., 9, 10) was used to collect data from the student-athletes. The questionnaire sought information on benefits (13 items) and challenges (10 items) of participation in Varsity tournaments. Each item was scored on a five-point Likert scale ranging from 1 (strongly disagree) to 5 (strongly agree). The Cronbach's alpha coefficient for the entire instrument was 0.87 , indicating that it was higher than the benchmark of 0.70 (12) and was thus considered reliable for data collection. The questionnaire was content-validated by a panel of three university professors in the areas of physical education, sport science, and management who reviewed the initial draft of the instrument and 
confirmed its suitability to address the research questions.

Data Collection. Before data collection, ethics approval was obtained from the Faculty Committee for Research Ethics of the Tshwane University of Technology. The participants were approached and requested to complete an informed consent form which was accompanied by an information leaflet providing all necessary details concerning the research. The participants were informed that the information obtained was strictly confidential and that data would be coded and analyzed such that they are not traceable to specific individuals. They were also advised to withdraw from the study at any stage or decline to participate without any consequences. The targeted participants at various universities in Gauteng Province were approached to participate in the study and data subsequently collected from those who consented to provide information for the study. Thereafter, questionnaires were distributed to the student-athletes to fill before or after their training sessions.

Data Analysis. Descriptive statistics such as means, standard deviations, percentages, and frequency counts were used to analyze the data. Principal components analysis (PCA) was computed to reduce the number of items and group them into meaningful units (13). An independent $t$-test was undertaken to compare gender differences on the benefits of/and challenges regarding participation in varsity competitions. A probability level of $p<0.05$ was used to indicate statistical significance. All data analyses were undertaken using the SPSS version 26.

\section{RESULTS}

The appropriateness of the data obtained for factor analysis was evaluated before PCA was undertaken. Specifically, Bartlett's Test of Sphericity $\left(\mathrm{x}^{2}=1470.99 ; d f=231 ; p<0.001\right)$ was significant, and the Kaiser-Meyer-Olkin (KMO) statistic of 0.80 was higher than the acceptable value of 0.60 (13). As Bartlett's Test of Sphericity was statistically significant, the factorability of the correlation matrix was supported (12). PCA results showed a two-factor solution, which explained $35.2 \%$ of the total variance. One item from the pattern matrix was removed because it had a factor loading of less than 0.30 , in which 22 items were retained. Consequently, PCA was further conducted on the remaining 22 items, which accounted for $36.62 \%$ of the overall variance of the two-component structure. The first factor, the benefits of participating in varsity tournaments, had an eigenvalue of 5.44 and consisted of 13 items that explained $24.70 \%$ of the total variance. The second factor, the challenges of participating in competitions, had an eigenvalue of 2.62 and contained nine items, which accounted for $11.92 \%$ of the pooled variance (Table 1$)$.

Table 1. Eigenvalues, Item Loadings, and the Percentage of Variance for PCA

\begin{tabular}{l|c}
\hline Variable & F1 \\
\hline To receive incentives and awards for performing well & 0.74 \\
\hline To stay at hotels & 0.73 \\
\hline To make headlines in newspapers and social media platforms & 0.73 \\
\hline To appear on television & 0.72 \\
\hline To enjoy good meals & 0.71 \\
\hline To travel by air & 0.70 \\
\hline To be popular among fellow students, staff members and community at large & 0.65 \\
\hline To complete my studies on record time due to a 60\% credit weight rule & 0.60 \\
\hline To be scouted by professional teams & 0.59 \\
\hline To make friends & 0.56 \\
\hline To make my family proud by completing my studies in record time & 0.52 \\
\hline To enjoy and have fun & 0.49 \\
\hline To receive payment & 0.41 \\
\hline There is no tutor in my department to assist me in catching up with my school Work & 0.67 \\
\hline Some of my lecturers do not give me permission to participate in matches & 0.64 \\
\hline I am worried about my safety and security during training and matches & 0.63 \\
\hline My institution has no dedicated sports official to advise me on my studies & 0.56 \\
\hline I am afraid of being injured during training and matches & 0.54 \\
\hline Match fixtures clash with my studies (e.g., unable to attend some classes due to travelling) & 0.49 \\
\hline My parents/guardians pressurise me to do well in my studies & 0.40 \\
\hline I struggle to get transport back home after training because I live off-campus & 0.38 \\
\hline My institution does not provide me with playing equipment & 0.36 \\
\hline Percentage of variance & 11.92 \\
\hline Eigenvalues & 2.62 \\
\hline
\end{tabular}

$$
\text { F1 = Factor 1. F2 = Factor } 2 .
$$


Table 2 shows the means and standard deviations on students' benefits of participating in Varsity Sports and Cup competitions. Overall, the most important benefits identified by studentathletes were, "To enjoy and have fun" ( $M=4.42$, $\mathrm{SD}=0.83$ ), "To make my family proud by completing my studies in record time" $(\mathrm{M}=4.35$, $\mathrm{SD}=1.00)$, "To make friends" $(\mathrm{M}=4.32, \mathrm{SD}=0.92)$, "To complete my studies on record time due to $60 \%$ credit weight rule" $(\mathrm{M}=4.05, \mathrm{SD}=1.05)$, "To receive incentives and awards for performing well" $(\mathrm{M}=4.04, \mathrm{SD}=1.29)$, "To appear on television"
$(\mathrm{M}=4.00, \mathrm{SD}=1.20)$ and "To be scouted by professional teams" $(\mathrm{M}=3.99, \mathrm{SD}=1.15)$. Male athletes had significantly higher averages than female participants in the following variables: 'To be scouted by professional teams' $(\mathrm{M}=4.17$, $\mathrm{SD}=1.08, \mathrm{p}=0.001)$, 'To stay at hotels' $(\mathrm{M}=4.13$, $\mathrm{SD}=1.14, \mathrm{p}=0.01)$, 'To travel by air' $(\mathrm{M}=3.90$, $\mathrm{SD}=1.25, \mathrm{p}<0.001)$, “To enjoy good meals' $(\mathrm{M}=3.83, \mathrm{SD}=1.17, \mathrm{p}=0.02)$, 'To make headlines in newspapers and social media platforms' $(\mathrm{M}=3.61, \mathrm{SD}=1.16, \mathrm{p}=0.04)$, and 'To receive payment' $(\mathrm{M}=3.16, \mathrm{SD}=1.59, \mathrm{p}=0.001)$.

Table 2. Gender-Based Benefits for Participating in Varsity Competitions

\begin{tabular}{|c|c|c|c|c|}
\hline Variable & All & Male & Female & Sig. \\
\hline To be scouted by professional teams & $3.99(1.15)$ & $4.17(1.08)$ & $3.60(1.20)$ & $0.001 *$ \\
\hline $\begin{array}{l}\text { To be popular among fellow students, staff members and the } \\
\text { community at large }\end{array}$ & $3.36(1.23)$ & $3.41(1.21)$ & $3.25(1.29)$ & 0.37 \\
\hline To enjoy and have fun & $4.42(0.83)$ & $4.36(0.87)$ & $4.56(0.73)$ & 0.11 \\
\hline To appear on television & $4.00(1.20)$ & $4.05(1.12)$ & $3.88(1.34)$ & 0.34 \\
\hline To make headlines in newspapers and social media Platforms & $3.49(1.24)$ & $3.61(1.16)$ & $3.23(1.36)$ & $0.04 *$ \\
\hline To travel by air & $3.67(1.41)$ & $3.90(1.25)$ & $3.18(1.61)$ & $0.00 *$ \\
\hline To stay at hotels & $3.98(1.26)$ & $4.13(1.14)$ & $3.65(1.46)$ & $0.01 *$ \\
\hline To receive incentives and awards for performing well & $4.04(1.29)$ & $4.12(1.05)$ & $3.86(1.27)$ & 0.13 \\
\hline $\begin{array}{l}\text { To complete my studies on record time due to } 60 \% \text { credit weight } \\
\text { rule }\end{array}$ & $4.05(1.05)$ & $4.09(0.99)$ & $3.95(1.16)$ & 0.37 \\
\hline To enjoy good meals & $3.69(1.18)$ & $3.83(1.17)$ & $3.42(1.17)$ & $0.02 *$ \\
\hline To make friends & $4.32(0.92)$ & $4.36(0.83)$ & $4.23(1.09)$ & 0.34 \\
\hline To make my family proud by completing my studies in record time & $4.35(1.00)$ & $4.36(0.92)$ & $4.32(1.15)$ & 0.81 \\
\hline To receive payment & $2.74(1.62)$ & $3.16(1.59)$ & $1.86(1.31)$ & $0.00 *$ \\
\hline
\end{tabular}

Table 3 presents the challenges encountered by student-athletes when participating in Varsity Sports and Cup tournaments. The most critical challenges encountered by the athletes were, "Match fixtures clash with my studies (e.g., unable to attend some classes due to traveling)" $(\mathrm{M}=3.41$, $\mathrm{SD}=1.36$ ), "My parents/guardians pressurize me to do well in my studies" (M=3.27, $\mathrm{SD}=1.42)$, "My institution does not provide me with playing equipment" $(\mathrm{M}=2.98, \mathrm{SD}=1.50)$, "I am afraid of being injured during training and matches" $(\mathrm{M}=2.60, \mathrm{SD}=1.41)$, "Some of my lecturers do not give me permission to participate in matches" $(\mathrm{M}=2.25, \mathrm{SD}=1.34)$ and "There is no tutor in my department to assist me in catching up with my school work" $(\mathrm{M}=2.22, \mathrm{SD}=1.29)$. A significant difference was observed between male and female student-athletes regarding the following variable: 'I struggle to get transport back home after training because 'I live off-campus' ( $\mathrm{t}_{(200)}=2.10, \mathrm{p}=0.03$ ).

\section{DISCUSSION}

In this study, the need for enjoyment and having fun was reported as the most important benefit of participation in Varsity Sports and Cup competitions. This finding is consistent with that of Cooper, Schuett, and Phillips (14), who reported that the enjoyment motive was ranked with the highest mean score by university students in the South Eastern region of the United States of America. This is a positive finding because intrinsic motivation encourages and sustains participation in sport compared to extrinsic motivation (14). Therefore, students are motivated to participate in the sport when their interests are identified, and intramural activities that satisfy those interests are organized for them. Therefore, in situations where participants participate in a sports program out of interest or enjoyment, such programs should be modified to maximize the motive $(15,16)$.

Other benefits of participation in Varsity Sports and Cup competitions as perceived by the students included completing their studies in record time and making their families proud. Given that most student-athletes do not achieve the goal of becoming professionals, they need to maximize any available opportunities related to 
educational and personal development (17). The student-athletes also reported that the 60-credit rule introduced by the management of the Varsity Sports and Cup competitions assisted them in completing their studies as scheduled. The Varsity Sports and Cup tournaments introduced the 60-credit rule to ensure that their sports engagement does not negatively affect their academic performance. A player who does not obtain the minimum threshold score (i.e., $60 \%$ average score) jeopardizes his/her chances of participating in Varsity Sports and Cup tournaments and would be disqualified. While this system is new in the South African context, it has been in existence in the United States since 2003 (17). The rationale for implementing this system was to evaluate the performances of student-athletes' through a team-based system which accounts for eligibility and retention every academic year (16).

Table 3. Challenges of Participating in Varsity Sports and Cup Competitions Based on Gender

\begin{tabular}{|c|c|c|c|c|}
\hline Variable & All & Male & Female & Sig. \\
\hline My parents/guardians pressurise me to do well in my studies & $\begin{array}{c}3.27 \\
(1.42)\end{array}$ & $\begin{array}{c}3.33 \\
(1.38)\end{array}$ & $\begin{array}{c}3.14 \\
(1.50)\end{array}$ & 0.36 \\
\hline $\begin{array}{l}\text { Match fixtures clash with my studies (e.g., unable to attend some classes } \\
\text { due to travelling) }\end{array}$ & $\begin{array}{c}3.41 \\
(1.36)\end{array}$ & $\begin{array}{c}3.43 \\
(1.30)\end{array}$ & $\begin{array}{l}3.35 \\
(1.47)\end{array}$ & 0.69 \\
\hline My institution has no dedicated sports official to advise me on my studies & $\begin{array}{c}2.21 \\
(1.24)\end{array}$ & $\begin{array}{c}2.24 \\
(1.25)\end{array}$ & $\begin{array}{l}2.14 \\
(1.24)\end{array}$ & 0.59 \\
\hline $\begin{array}{l}\text { There is no tutor in my department to assist me in catching up with my } \\
\text { schoolwork }\end{array}$ & $\begin{array}{c}2.22 \\
(1.29)\end{array}$ & $\begin{array}{c}2.27 \\
(1.26)\end{array}$ & $\begin{array}{c}2.11 \\
(1.36)\end{array}$ & 0.41 \\
\hline I am afraid of being injured during training and matches & $\begin{array}{c}2.60 \\
(1.41)\end{array}$ & $\begin{array}{c}2.49 \\
(1.35)\end{array}$ & $\begin{array}{c}2.83 \\
(1.51)\end{array}$ & 0.11 \\
\hline $\begin{array}{l}\text { I struggle to get transport back home after training because I live off- } \\
\text { campus }\end{array}$ & $\begin{array}{c}1.83 \\
(1.25)\end{array}$ & $\begin{array}{c}1.96 \\
(1.26)\end{array}$ & $\begin{array}{c}1.56 \\
(1.19)\end{array}$ & $0.03 *$ \\
\hline My institution does not provide me with playing equipment & $\begin{array}{c}2.98 \\
(1.50)\end{array}$ & $\begin{array}{c}2.87 \\
(1.49)\end{array}$ & $\begin{array}{c}3.22 \\
(1.51)\end{array}$ & 0.13 \\
\hline I am worried about my safety and security during training and matches & $\begin{array}{c}1.79 \\
(1.11)\end{array}$ & $\begin{array}{c}1.82 \\
(1.07)\end{array}$ & $\begin{array}{c}1.74 \\
(1.19)\end{array}$ & 0.63 \\
\hline Some of my lecturers do not give me permission to participate in matches & $\begin{array}{c}2.25 \\
(1.34) \\
\end{array}$ & $\begin{array}{c}2.25 \\
(1.31)\end{array}$ & $\begin{array}{c}2.25 \\
(1.41) \\
\end{array}$ & 0.99 \\
\hline
\end{tabular}

Making friends was also identified as an essential benefit for participating in sports. A similar finding was reported by Kubayi and Amusa (18), who indicated that having a friend was identified as a helpful cue for participating in sports among students in the Hlanganani rural area of Limpopo Province, South Africa. King, Tergerson and Willson (19) have emphasized the role of friendship by reporting that a friend acts as a support system, someone to exercise with, and a source of motivation to sustain sports participation. Through sports participation, adolescents are provided opportunities to develop friendships, connect with others socially, and continue being physically active $(18,19)$. Therefore, in planning sports programmes, sport coaches should incorporate strategies that promote socialisation among students (17).

Another important benefit of participating in university sport, as indicated by the studentathletes, was to receive incentives and awards. Weinberg and Gould (16) reported that extrinsic rewards should be provided to athletes who should be informed that the reward is about their competence rather than a control issue. In a comparative analysis of the management of sport at two South African universities, i.e., Universities of the North and Venda, Amusa and Toriola (20), emphasized the need for the universities to develop sustainable sports policies and provide necessary incentives for effective sports promotion. However, it should be noted that external rewards should be contingent on behavior and be earned. As much as extrinsic rewards are used sparingly, they can assist in motivating students to participate in sports. For example, rewarding athletes for merely participating in sport may be meaningless, but providing rewards for winning a competition could fuel motivation (14).

It was also of interest to the present study to discuss challenges encountered by studentsathletes while participating in Varsity Sports and Cup competitions. The most important barrier experienced by the students-athletes was the conflict between their training or match fixtures with their studies. For example, some indicated that they were unable to attend several classes due 
to sport-related engagements. This finding could be explained in the light that student-athletes attend daily practices, travel across the country to participate in competitions, and are also required to attend lectures as an important academic requirement (20). Consequently, the athletes may find it difficult to work on their class activities, homework, assignments, and tests as well as undertake other class activities such as workintegrated learning and internships (20). Therefore, the time and effort spent by students to carry out academic activities may become limited and less important (17), thereby pressurizing them considerably.

Studies on the benefits and barriers of university sport participation have also been conducted in other countries. A study carried out among university students in Canada (11) identified time constraints, limited sports activities, and high workload as barriers to sport participation. Another research conducted in France (10) reported that the students experienced intrapersonal, interpersonal, and structural barriers to physical activity and sport participation. In their study of female students' perceptions of the barriers to participation in physical and sports activities at Al-Hussein Bin Talal University, Jordan, Al-Tawel \& AlJa'afreh (21) reported some constraints, namely social, religious, academic, and psychological barriers. A national higher education sport participation survey in the UK indicated that only $48 \%$ of the students were satisfied with sports provision at their institutions (22). Many of the students surveyed suggested introducing a variety of sports activities, especially for women, and more flexible times that would afford them greater opportunity to engage in sport. These studies show that barriers to students' sport participation are similar across countries.

Within the South African context, as it is in many other countries, student-athletes have huge expectations to perform successfully in sports competitions despite having limited time to cope with the demands of academic requirements (17). Since sports training and competition schedules sometimes prevent student-athletes from meeting their academic commitments and career aspirations, it is important that universities and/or management of Varsity Sports and Varsity Cup properly regulate the training and competition schedules to ensure that these do not disrupt students' normal academic activities. For example, in 1991, the NCAA introduced new regulations designed to limit student-athletes' daily structured sports practice time to four hours or less and 20 hours weekly (e.g., practice, conditioning, team meetings, competition). The discernible efforts made by the NCAA to regulate practice time have proved to be successful and have increased the graduation rate among studentathletes (17). Therefore, similar regulations on practice times should be implemented within the South African context to cater to the needs of student-athletes.

\section{CONCLUSION}

This study showed that enjoyment, to make their families proud, to make friendships, to complete their studies on time, to receive incentives and awards for performing well, to be on television, and to be scouted by professional teams were perceived as the most important benefits for participating in varsity competitions by South African student-athletes. Major challenges faced by the athletes included match fixtures clashing with academic timetables, parents/guardians pressurizing them to excel academically, inadequate sporting equipment, fear of injury, and poor academic support needed to catch up with schoolwork.

\section{APPLICABLE REMARKS}

- To alleviate the barriers of participating in varsity competitions by South African studentathletes, student-athletes should be provided necessary support such as academic advisers and extra classes to help them excel in their studies.

- Such interventions would help to increase the success rate of the student-athletes and promote their sporting careers.

- As student-athletes are first and foremost students, they should not be regarded as athletestudents.

- Rather, they should be provided all the needed support which would empower them to succeed in their chosen fields.

\section{REFERENCES}

1. Segwaba J, Vardhan D, Duffy P. Coaching in South Africa. Int Sport Coach J. 2014;1:33-41. doi: 10.1123/iscj.2013-0042 
2. National Department of Sport and Recreation. Getting the Nation to Play. Pretoria, South Africa: Government Printers1995.

3. Kubayi A, Didymus FF, Morris-Eyton H, Jooste J. Design and preliminary validation of the barriers to sports coaching questionnaire for women in South Africa: An application of the ecological model. $J$ Sports Sci. 2020:1-8. doi: 10.1080/02640414.2020.1792162 pmid: 32662352

4. Tesnear S, Surujlal J. Women's rugby: A qualitative study of female players' experiences. Afr J Phys Health Educ Recreat Dance. 2012;1(2):354-368.

5. Kubayi NA. Barriers and hindrances experienced by sport coaches in Gauteng Province. Johannesburg: University of Johannesburg; 2015.

6. Amusa LO, Toriola AL, Goon DT. Physical education and school sport in South Africa. Global J Health Phys Educ Pedagogy. 2013;2(3):187-196.

7. Nolan VT, Sandada M, Surujlal J. Perceived benefits and barriers to physical exercise participation of first year university students. Afr J Phys Health Educ Recreat Dance. 2011:56-69.

8. Kubayi NA, Nthangeni AS, Toriola AL, Haycock E. Perceived barriers to female sports participation: A case study of Tshwane University of Technology, Pretoria, South Africa. Afr J Phys Health Educ Recreat Dance. 2013;11(1-2):442-451.

9. Varsity Sports Booklet. Concise rules, regulations and processes.: University Sport Company; 2015.

10. Montagni I, Vialemaringe M, Tzourio C. Sport practice and perceptions in university students: a mixedmethods study. Int Sport Sci Stu Stud. 2020;2(1):1-15.

11. Thomas AM, Beaudry KM, Gammage KL, Klentrou P, Josse AR. Physical Activity, Sport Participation, and Perceived Barriers to Engagement in First-Year Canadian University Students. J Phys Act Health. 2019;16(6):437-446. doi: 10.1123/jpah.2018-0198 pmid: 31130058

12.Pallant J. SPSS survival manual: A step by step guide to data analysis using SPSS. Australia: Allen \& Unwin; 2011.

13. Kaiser HF. An index of factorial simplicity.: Psychometrika; 1974.

14. Cooper N, Schuett PA, Phillips HM. Examining intrinsic motivations in campus intramural sports. Recreat Sports J. 2012;36:25-36. doi: 10.1123/rsj.36.1.25

15. Girginov V, Sandanski I. Understanding the changing nature of sports organisations in transforming societies. Sport Manage Rev. 2008;11:21-50. doi: 10.1016/S1441-3523(08)70102-5

16. Weinberg RS, Gould D. Foundations of sport and exercise psychology. Champaign, IL: Human Kinetics; 2018.

17. Hazzaa RN, Sonkeng K, Yoh T. Antecedents and consequences of student-athletes' contentment with academic services. J Intercollegiate Sport. 2018;11:65-81. doi: 10.1123/jis.2017-0041

18. Kubayi NA, Amusa LO. Correlates of physical activity participation among secondary school students in Hlanganani rural area of Limpopo Province, South Africa. Afr J Phys Health Educ Recreat Dance. 2014;20(3):1173-1181.

19. King KA, Tergerson JL, Wilson BR. Effect of social support on adolescents' perceptions of and engagement in physical activity. J Phys Act Health. 2008;5(3):374-384. doi: 10.1123/jpah.5.3.374 pmid: 18579916

20. Amusa LO, Toriola AL. Developing sports in South African universities: An overview of problems and prospects at the Universities of the North and Venda. J Human Mov Stud. 2002;44:61-77.

21.Al-Tawel AM, AlJa'afreh IA. A study of female students perceptions of the barriers to participate in physical and sports activities at Al-Hussein Bin Talal University. J Edu Prac. 2017;8(11):1-10.

22.TNS BMRB. Higher Education Sport Participation and Satisfaction Survey. London, UK: Sport England; 2014. 